\title{
A root cause analysis and a risk evaluation of PV balance of systems failures
}

\author{
Loredana Cristaldi, Mohamed Khalil, Payam Soulatiantork
}

DEIB, Politecnico di Milano, Milano, Italy

\begin{abstract}
The Photovoltaic (PV) system is divided mainly into two subsystems; PV modules and a Balance of System (BoS) subsystems. This work shows two approaches for a reliability analysis on the subsystem level of aBoS: Failure mode effects criticality analysis (FMECA) and a Markov Process. FMECA concerns the root causes of failures and introduces prioritization numbers to highlight critical components of a BoS. Meanwhile, a Markov process is a reliability methodology that aims to predict the probability of success and failure of a BoS. In this way, a Markov process is a supportive tool for helping decision-makers to judge the criticality of failures associated with the operation of PV systems. Results show that the PV inverter contributes significantly to the failures of a BoS. Accordingly, further investigations are conducted on a PV inverter to prioritize the maintenance activities by determining the risk priority number of its component failures through quantitative CA. The novelty of the proposed methodologies stems from analyzing the roots of failure causes of BoS components and estimating the probability of failure of these components in order to improve the early development of a BoS, enhance maintenance management, and satisfy the demanding reliability by electric utilities.
\end{abstract}

\section{Section: RESEARCH PAPER}

Keywords: reliability assessment; root cause analysis of failures; Markov process; photovoltaic systems; balance of system; FMECA

Citation: Loredana Cristaldi, Mohamed Khalil, Payam Soulatiantork, A root cause analysis and a risk evaluation of PV balance of systems failures, Acta IMEKO, vol. 6, no. 4, article 18, December 2017, identifier: IMEKO-ACTA-06 (2017)-04-18

Section Editor: Lorenzo Ciani, University of Florence, Italy

Received September 28, 2016; In final form October 19, 2017; Published December 2017

Copyright: (C) 2017 IMEKO. This is an open-access article distributed under the terms of the Creative Commons Attribution 3.0 License, which permits unrestricted use, distribution, and reproduction in any medium, provided the original author and source are credited

Corresponding author: Mohamed Khalil, mohamedmahmoud.khalil@polimi.it

\section{INTRODUCTION}

A Balance of System (BoS) comprises all the non-module components of Photovoltaic (PV) power plants. Failures of BoS components are the major reason behind the presence of non-producing modules in PV field. Ten years survey [1] was carried out by Sandia National Laboratories on 35 PV systems, and results showed that failure of BoS components such as switches, fuses, $\mathrm{dc}$ contactors and surge arrestors were responsible for $54 \%$ of the non-producing modules that were found, around 10,000 non-working modules. The layout of the PV system varies according to the architecture design; it can be a single- inverter system where all the strings are connected to a central inverter: a string-inverter system where each string has its own inverter, or a multi-inverter system where the PV field is divided into groups of strings connected to an inverter. Accordingly, BoS varies in design according to the layout of the PV systems. The most optimized BoS whose components are the basic for any design is presented in Figure 1. The failure of any of its components contributes significantly in the failures of PV system. It is worth mentioning that protection equipment is excluded since the utility switchgear is sufficient for the protection purposes of an optimum BoS. It is worth noting that the utility switchgear is full of protection relays and tripping equipment that trip immediately the PV plant in case of any power faults.

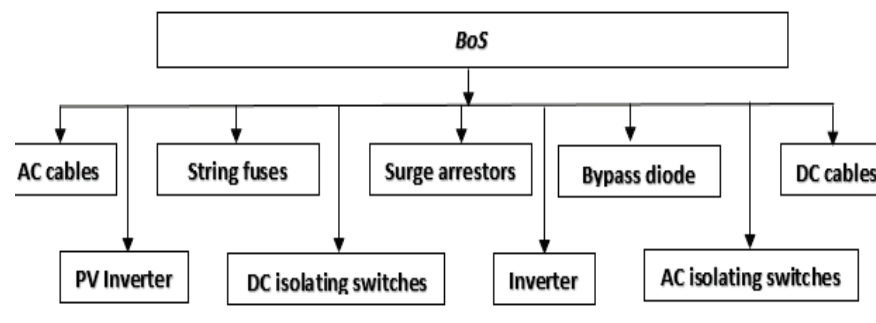

Figure 1. BoS Components. 
In literature, most of the studies focus on PV modules reliability evaluation and only very limited publications consider the reliability of BoS. Among these publications, a qualitative reliability analysis is presented in [2] using fault tree analysis and other efforts in [3] investigated the reliability of both PV modules and BoS using Petri's networks in order to estimate the lifetime, reliability, and availability.

In general, the first step towards enhancing a system's reliability is to detect the root causes of systems' failures. In this respect, Failure Mode Effect Criticality Analysis (FMECA), a well-known methodology, is used in order to analyze the failure causes of systems. It focuses mainly on identifying the possible failure causes. In addition, it is one among several methods used for risk assessment and management by selecting the most proper maintenance strategies to enhance the system performance.

A recent research [4] applied FMECA on a PV system designed by Brookhaven National Laboratory and results show that inverter and ground system of the PV system have the highest Risk Priority Number (RPN). It provides a strong investigation of the FMECA on all PV system components; however [4] considered a specific design and did not list recommended actions to limit the failure causes, and the potential failure modes were listed without highlighting the contribution of each system component in the failure of the whole PV system.

On the other hand, the FMECA methodology, in this work, is limited with more details to BoS only whose components are more optimized. The failure causes of each component are studied in detail, and recommended actions are listed. In addition, a prioritization number is assigned to each failure, based on IEC-60182, to improve the maintenance activities. Moreover, a further reliability investigation is carried out by a Markov Process to be a supportive tool along with FMECA in case of any confusion on judging the priority number by maintenance management. More details on the confusion of judging RPN is available in [5].

Both techniques illustrate results that can be utilized during the design phase in order to reduce the major field problems and improve the reliability of the systems. Also, they can be used during the operation phase by improving the maintenance management and reducing the failure probability of occurrence.

This paper is organized as follows; Section 2 provides a general overview on the failure causes of $\mathrm{BoS}$ components; Section 3 presents FMECA results; Section 4 shows the Markov process conducted on BoS; and Section 5 focuses only on Criticality Analysis (CA) of the PV inverter. Finally, Section 6 includes the conclusions.

\section{BALANCE OF SYSTEM FAILURE CAUSES}

Mapping the failure causes is the first step towards the reliability analysis for determining the underlying failures and enhancing failure prediction methods. Figure 2 shows a schematic diagram of optimized BoS that consists of the necessary components needed to be installed on a PV string. In this section, the failure cause of each BoS's component is described in detail.

\section{1. $A C$ and $D C$ cables}

AC and DC cables represent the veins of PV systems and their failures result in partial or complete shutting down of the PV plant. In addition, cable problems at the module levels can lead to a severe mismatch for other modules cabled in the same

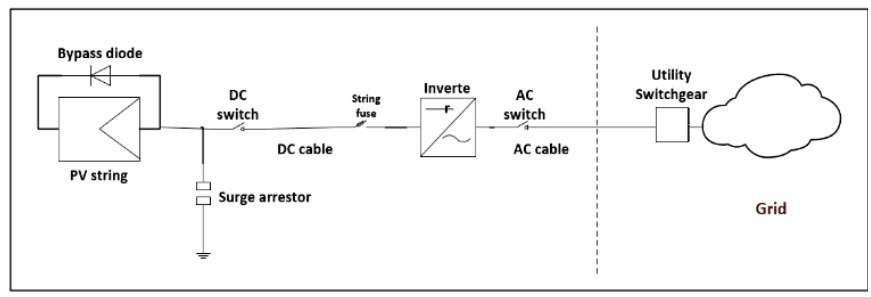

Figure 2. BoS of PV string.

parallel block [6] and result in drop of the output power. Loose cables by poor workmanship due to excess torque and pressure during installation, undersized cables, overvoltage and overcurrent, insufficient protection are the main causes for PV cabling.

\subsection{Bypass diode}

Bypass diodes are usually supplied inside the module junction box or manufactured only inside PV modules for sophisticated module types only [7]. A study was carried out in [8] on 1272 modules showed that $47 \%$ of the modules have defective bypass diodes and $3 \%$ of the defective bypass diode caused burn mark on the modules. Generally, the main function of a bypass diode is to allow the current to pass around the shaded or cracked cells and thereby reduces the power losses within the module itself. Hence, hot spots will be avoided and a long lifetime of the system will be guaranteed [9]. Bypass diodes have a junction temperature reaching up to $150-200{ }^{\circ} \mathrm{C}$ and they possess a significant self-heating [10], however the main reason of their failures is the applicable thermal stress during their operation because they are not exposed to sufficient air flow for cooling.

\subsection{String fuse}

Depending on the necessary capacity of a PV system, there might be several strings which are connected in parallel for higher currents and more power. Only PV systems that have at least three strings require a fuse to be placed on each string. PV systems which have less than three strings will not generate sufficient fault current and do not present a safety hazard [11]. In general, a fuse can be considered as a conductor with a relatively low melting temperature surrounded by a dielectric insulator. String fuses have different failure modes that can be summarized into false operation, design factor, cracks of dielectric packaging and shift in fuse resistance; the resistance is increased during the normal operation, or it becomes relatively low during tripping [12],[13]. Moreover, the fatigue factor contributes to the aforementioned failure modes; string fuses are subjected to wear out since switching on and off would heat up and cool down the fuses. Consequently, fuse fatigue is developed by time.

\section{4. $A C$ and $D C$ isolation switches}

IEEE Std C37.100-1992 [14] defines the isolating switch as a mechanical switching device used for changing the connection in a circuit or for isolating a circuit or equipment from the power source. In PV systems, the installation of a DC switch on each string is necessary for maintenance purposes of strings in order to avoid shutting down the inverter and consequently disconnecting the whole strings.

On the AC side, the cable connecting the inverter to the grid is usually dimensioned to carry currents higher than the maximum current which the inverter can deliver. So a 
protection against overload is not necessary and a circuit breaker at the utility switchgear is sufficient to protect against faults from the grid. However, an AC switch is still necessary and should be installed for maintenance purposes of the inverter [15].

The most common failure mode of isolating switches is a failure in the mechanical mechanism; thus the switch fails to open or close, and contacts will carbonize; that results in local temperature rise and reduction of contact quality.

\subsection{Inverter}

In a grid-connected PV plant, the inverter represents an expensive and complex key component. A typical three-phase PV inverter includes: IGBT Power modules, cooling fans, control software and DC link capacitors implemented on Printed Circuit Boards (PCBs) in addition to AC \& DC contactors. An IGBT power module fails as a result of thermal runaway [16], ceramic substrate to base plate solder fatigue [17], partial discharge [18], and FWD if short circuited [19]. AC and DC contactors fail to open or close due to design defects, mechanical locks, failure of the tripping coil, arcs and overheating that cause degradation of the electric contacts. Solder fractures and cracks are the main failure causes of PCBs and result in overheating and gradual resistance increase of the solder joints [20]. The control software fails in case of improper design, absence of health monitoring facility and incapability to adapt the change in electrical and environmental parameters.

\subsection{Surge arrestors}

Surge arrestors are designed to isolate the PV circuit from the ground during normal voltage operation and to connect to ground when the voltage of the line exceeds the threshold value. In PV systems, they are installed to provide a complete protection against lightning and induced over-voltages. On the DC side, a surge protection device is always placed on the supply side of the inverter's isolating device in order to provide a complete protection when the isolating device is opened. In service, surge arrestors are exposed to frequent lightening that results in excessive overheating and leads to degradation of its characteristics. Also, moisture ingress can find its way inside the surge arrestor in case of sealing defects and contribute in dielectric degradation.

\section{FAILURE MODE EFFECT CRITICALITY ANALYSIS}

FMECA consists of two separate parts, the Failure Mode and Effects Analysis (FMEA) and the Criticality Analysis (CA). FMEA includes a list of possible equipment failure modes, reason of these failures, local and final effects that refer to the impact of each failure on the system element and the whole system respectively, and the alternative recommended corrective actions to avoid each failure [21].

On the other hand, Criticality Analysis plans and focuses the maintenance activities according to a set of priorities by giving failures with the highest risk the highest priority.

\subsection{FMEA on BoS}

The analysis starts with gathering information on the functions and failures of BoS components. The impact of each failure cause for each component is investigated on the component itself and the PV modules and strings, stated in the local effect. Afterwards, the impact of each component failure, on the whole PV system, is stated in final effect. Finally, the most proper recommendations are given to reduce the failure of each BoS component. The working of FMEA on BoS is listed in Table 2.

\subsection{CA on BoS}

The criticality is a manner to quantify how much attention is necessary to pay about determined component failure or event; this is carried out either through qualitative means based on experience and field background or quantitative means if previous failure data are available. Currently, field data are not available for $\mathrm{BoS}$, therefore, a qualitative $\mathrm{CA}$ is the most relevant means to evaluate $\mathrm{CA}$. This is managed by assigning each failure mode to a Risk Priority Number (RPN), defined by $\mathrm{RPN}=\mathrm{O} \times \mathrm{S} \times \mathrm{D}$, where $\mathrm{S}$ represents a scale for the failure severity and the risks behind the failure occurrence, $\mathrm{O}$ denotes the probability of failure mode occurrence, and $\mathrm{D}$ means detection, and represents the possibility to recognize the failure before the system or the customers are affected. For expectation purposes of components' failures, an IEC evaluation criterion is selected as shown in Table 1.

In the CA evaluation, the occurrence is evaluated in accordance to the failure rate of the BoS components stated in Table 3; the severity is based on the expected interruption of power and possible damages to PV modules, and detection considers the fault detection tools and equipment in the field. The evaluated RPN is presented in Figure 3.

It is depicted from Figure 3 that the inverter has the highest RPN because of the complexity of its components. The bypass diode follows the inverter since its rate of occurrence is quite high compared to the rest of other components; its failure results in burned marks on PV modules and reduction of

Table 1. IEC-60182 evaluation criteria for occurrence, severity, detection.

\begin{tabular}{lccc}
\hline \multicolumn{1}{c}{$\begin{array}{c}\text { Occurrence } \\
\text { ( O) }\end{array}$} & $\begin{array}{c}\text { Severity } \\
\text { ( S) }\end{array}$ & $\begin{array}{c}\text { Detection } \\
\text { ( D) }\end{array}$ & Ranking \\
\hline Failure is unlikely & $\begin{array}{c}\text { No } \\
\text { discernible } \\
\text { effect }\end{array}$ & $\begin{array}{c}\text { Almost } \\
\text { certain }\end{array}$ & 1 \\
\hline $\begin{array}{l}\text { Low: } \\
\text { Relatively few } \\
\text { failures }\end{array}$ & Very minor & Very high & 2 \\
\cline { 2 - 4 } $\begin{array}{l}\text { Moderate: } \\
\text { Occasional failures }\end{array}$ & Minor & High & 3 \\
\cline { 2 - 4 } & Very low & $\begin{array}{c}\text { Moderately } \\
\text { high }\end{array}$ & 4 \\
\cline { 2 - 4 } $\begin{array}{l}\text { High: } \\
\text { Repeated Failures }\end{array}$ & Moderate & Moderate & 5 \\
\cline { 2 - 4 } $\begin{array}{l}\text { Very high: } \\
\text { Failure is almost } \\
\text { unavoidable }\end{array}$ & Hery high & Low & 7 \\
\hline
\end{tabular}

Table 3. Component adopted failure rates.

\begin{tabular}{cc}
\hline Component & Failure rate \\
\hline Bypass diode & $0.027 \mathrm{f} /$ year [26] \\
DC switch & $0.0018 \mathrm{f} /$ year [27] \\
AC wire & $0.00011 \mathrm{f} /$ year. [28] \\
DC wire & $0.00042 \mathrm{f} /$ year. [28 ] \\
AC Switch & $0.0003 \mathrm{f} /$ year [27] \\
String fuse & $0.00017 \mathrm{f} /$ yr [26] \\
Photovoltaic inverter & $0.125 \mathrm{f} /$ year [25] \\
\hline
\end{tabular}




\begin{tabular}{|c|c|c|c|c|c|c|c|c|c|}
\hline 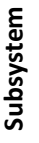 & $\begin{array}{l}\text { Outage } \\
\text { mode }\end{array}$ & Possible outage cause & Local effect & Final effect & $\begin{array}{l}\text { Compensating provision } \\
\text { against failure }\end{array}$ & $\mathbf{S}$ & 0 & D & RPN \\
\hline \multirow{5}{*}{ ヘૂ } & $\begin{array}{l}\text { AC Cables } \\
\text { DC cables }\end{array}$ & $\begin{array}{l}\text { Thermal expansion } \\
\text { and contraction. } \\
\text { Loose cables. } \\
\text { Undersized cables. } \\
\text { Overvoltage and over } \\
\text { current. }\end{array}$ & $\begin{array}{l}\text { Slow output power } \\
\text { degradation and } \\
\text { increased power } \\
\text { losses }\end{array}$ & $\begin{array}{c}\text { Shutdown of one or } \\
\text { more PV strings. } \\
\text { Arcs and fire risk }\end{array}$ & $\begin{array}{l}\text { Minimizing electrical } \\
\text { cables wiring, proper } \\
\text { design, sufficient } \\
\text { protection, using cable } \\
\text { ducts, routine visual } \\
\text { inspection }\end{array}$ & 3 & 3 & 2 & 12 \\
\hline & $\begin{array}{l}\text { Bypass } \\
\text { diodes }\end{array}$ & $\begin{array}{c}\text { Thermal stress, } \\
\text { insufficient cooling. } \\
\text { Over voltages and high } \\
\text { currents. } \\
\text { Insufficient rating }\end{array}$ & $\begin{array}{l}\text { Hot spots and burn } \\
\text { marks on PV module }\end{array}$ & $\begin{array}{l}\text { Bypass diode is open } \\
\text { circuited: no change } \\
\text { in output power. } \\
\text { Bypass diode short } \\
\text { circuited: Significant } \\
\text { drop of power. }\end{array}$ & $\begin{array}{l}\text { proper design, installing } \\
\text { surge arrestors }\end{array}$ & 5 & 6 & 2 & 60 \\
\hline & String fuses & $\begin{array}{l}\text { False operation. } \\
\text { Improper design, } \\
\text { cracks of dielectric } \\
\text { packaging. } \\
\text { Shift in fuse } \\
\text { resistance, Thermal } \\
\text { wear out. }\end{array}$ & $\begin{array}{l}\text { In closed circuit mode: } \\
\text { Slow output } \\
\text { degradation and } \\
\text { increase of power } \\
\text { losses. } \\
\text { In open circuit mode: } \\
\text { isolation of the one or } \\
\text { more strings }\end{array}$ & $\begin{array}{l}\text { Significant reduction } \\
\text { of output power }\end{array}$ & $\begin{array}{l}\text { Proper design, installing } \\
\text { surge arrestors. } \\
\text { Regular visual inspection }\end{array}$ & 3 & 2 & 3 & 18 \\
\hline & $\begin{array}{l}\text { DC isolating } \\
\text { switches } \\
\text { AC isolating } \\
\text { switches }\end{array}$ & $\begin{array}{c}\text { Mechanical } \\
\text { mechanism Failure, } \\
\text { improper design, } \\
\text { carbonized contacts }\end{array}$ & $\begin{array}{l}\text { Increase in contact } \\
\text { resistance and power } \\
\text { losses }\end{array}$ & $\begin{array}{l}\text { Partial or complete } \\
\text { shutdown of the PV } \\
\text { system }\end{array}$ & $\begin{array}{c}\text { Enhance periodic } \\
\text { maintenance and proper } \\
\text { inspection of operating } \\
\text { mechanism }\end{array}$ & 4 & $\begin{array}{l}5 \\
3\end{array}$ & $\begin{array}{l}2 \\
2\end{array}$ & $\begin{array}{l}40 \\
24\end{array}$ \\
\hline & $\begin{array}{l}\text { Surge } \\
\text { arrestors }\end{array}$ & $\begin{array}{l}\text { Excessive overheating } \\
\text { Sealing defects and } \\
\text { environmental } \\
\text { contamination }\end{array}$ & $\begin{array}{c}\text { Characteristics } \\
\text { degradation. } \\
\text { leakage current } \\
\text { increases and } \\
\text { dielectric integrity fails } \\
\text { to discharge over } \\
\text { voltages. }\end{array}$ & $\begin{array}{l}\text { Partial discharge } \\
\text { arching, induced } \\
\text { over voltages and } \\
\text { lightning strikes on } \\
\text { PV equipment }\end{array}$ & $\begin{array}{l}\text { Regular testing ( leakage } \\
\text { current and Meggar) } \\
\text { Visual inspection to avoid } \\
\text { dust accumulation and } \\
\text { sealing defects. } \\
\text { Maintaining and ensuring } \\
\text { proper grounding systems. }\end{array}$ & 2 & 2 & 3 & 12 \\
\hline
\end{tabular}

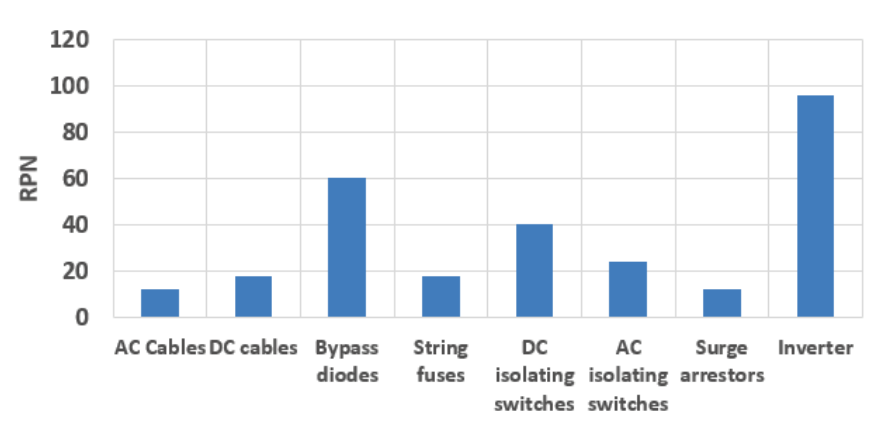

Figure 3. RPN of BoS components.

power. In the field, failure detection of the bypass diode is done by infrared cameras and signal transmitter devices. Both the inverter and bypass diode are the key elements for a safe system operation; therefore, it is recommended to conduct the aforementioned detection procedures of the bypass diodes along with the routine maintenance of the PV inverter in time. On the other hand, the surge arrestor has the lowest RPN, since it is very rarely when it fails in short circuit mode, and it is not opening the circuit in case of open circuit mode.

\section{MARKOV ANALYSIS ON BOS}

A Markov process is a sequences of random variables in which the future variable is determined by the present variable and independent on the way in which the present state arose from its predecessors. The analysis looks at a sequence of events and analyzes the tendency of one event to be followed by another [22]. This tendency is the probability evaluation of transition from one state to another until the system has reached the final state. Thus, a Markov process is defined by a process $\{p(t), t \geq 0\}$ with state space $X=\{0,1,2,3, \ldots . r\}$ and stationary transition probabilities:

$$
P_{i j}=\operatorname{Pr}(p(t)=j \mid p(0)=i) \text { for all } i, j \in X
$$

where $p(t)$ is a random variable denotes the state and belongs to state space $X$. The rate of change from one state to another is estimated based on the transient analysis point of view, through Kolmogorov forward equations, 


$$
\frac{\mathrm{d} p(t)}{\mathrm{d} t}=p(t) \cdot \mathbf{A}
$$

and

$$
\sum_{j=0}^{n} \mathrm{P}(t)=1
$$

where $\frac{\mathrm{d} p(t)}{\mathrm{d} t}$ is a vector that represents the state probability $p(t)$ at time $t$, and $\mathbf{A}$ is a matrix of transition probability between states. As the number of possible states are finite, (3) is necessary because the probabilities of all states at any time $t$ should equal 1 and the system can be in one and only one of these states. In case of zero repair rates, i.e. Poisson birth-death process, (2) can be rewritten as

$\frac{\mathrm{d} p_{i}(t)}{\mathrm{d} t}=-\sum_{i \neq j} \lambda_{i, j} P_{i}(t)+\sum_{i \neq j} \lambda_{j, i} P_{j}(t)$

Although a Markov process, from the theoretical viewpoint, is flexible and versatile, special precautions are necessary to deal about the difficulties of practical applications. The main problem is that the number of system states and possible transitions increases rapidly with the number of events in the system [23]. Therefore, assumptions become a necessity. The usual assumptions considered by current standards and references, i.e. IEC-61165 [23], IEC 61508[24], and [22], can be summarized as follows: i) failure and repair rate are constant, ii) failure and repair events are independent, iii) the transition probability from one state to another state occurs within a very small time interval, iv) only one event occurs at the same time.

In systems modelling without repairs, IEC-61165 [23] considered three possible states for the system: The up, degraded and absorbing states. The up state represents a system free of any failure. The degraded state is related to a system state whose performance meets the warranty limits although its operation is associated with failures. Absorbing states are the final states for the system when it falls. In the Markov process, states are absorbing if they are once reached by the system; the system will remain there forever.

The term BoS is a very general term since it includes all the non PV module components and it depends as well on the design of the PV system, whether it is a central inverter, a string-inverter system or a multi inverter PV system. Therefore, the reliability analysis is carried out on the BoS components of the PV string shown in Figure 2. It is assumed that the surge arrestor never fails in short circuit mode and it is not opening the circuit in case of failure; therefore it will be excluded from the Markov process analysis.

The major problem that always appears on any reliability study concerning the PV system is the lack of PV components failure information and absence of reliability, therefore the components failure rate of the BoS are gathered from literature [26]-[28] in Table 3. It is worth to mention that the inverter failure rate is calculated by considering one failure in 8 years [25] so the failure rate is 0.125 failure/year.

According to the string configuration shown in Figure 2, once any component fails the whole PV string fails; therefore, each components is assumed to have two states: up and down. All the possible scenarios for the failures of the string BoS components are listed in Table 4. Accordingly, the state transition diagram is illustrated in Figure 4. Consequently, the state equations of a string BoS can be estimated from (4) as follows:

$$
P_{0}^{*}(t)=-\left(\lambda_{1}+\lambda_{2}+\lambda_{3}+\lambda_{4}+\lambda_{5}+\lambda_{6}+\lambda_{7}\right) P_{0}(t)
$$

Table 4. System states.

\begin{tabular}{cc}
\hline State & Scenario \\
\hline 0 & All components work \\
1 & Bypass diode fails \\
2 & DC switch fails \\
3 & AC wire fails \\
4 & DC wire fails \\
5 & AC Switch fails \\
6 & String fuse fails \\
7 & Photovoltaic inverter fails
\end{tabular}

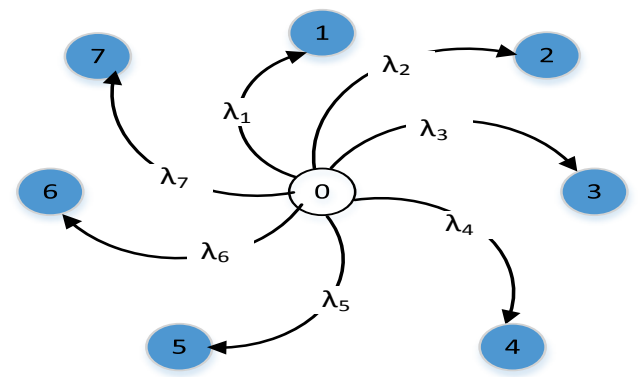

Figure 4. State transition diagram of string BoS failures.

From the definition, reliability is the probability to perform its required function without any failures, under given conditions and for a stated period of time. Therefore, the string BoS reliability is equal to the probability of state $0, P_{0}(t)$. Hence $R(t)$ is presented in Figure 5 .

Based on Figure 5, the MTTF of a string BoS is around 6 years which is close to the MTTF of the inverter. In order to highlight the impact of the inverter on the reliability of the string BoS, Figure 6 is given. The MTTF of the string BoS without the inverter is around 33 years.

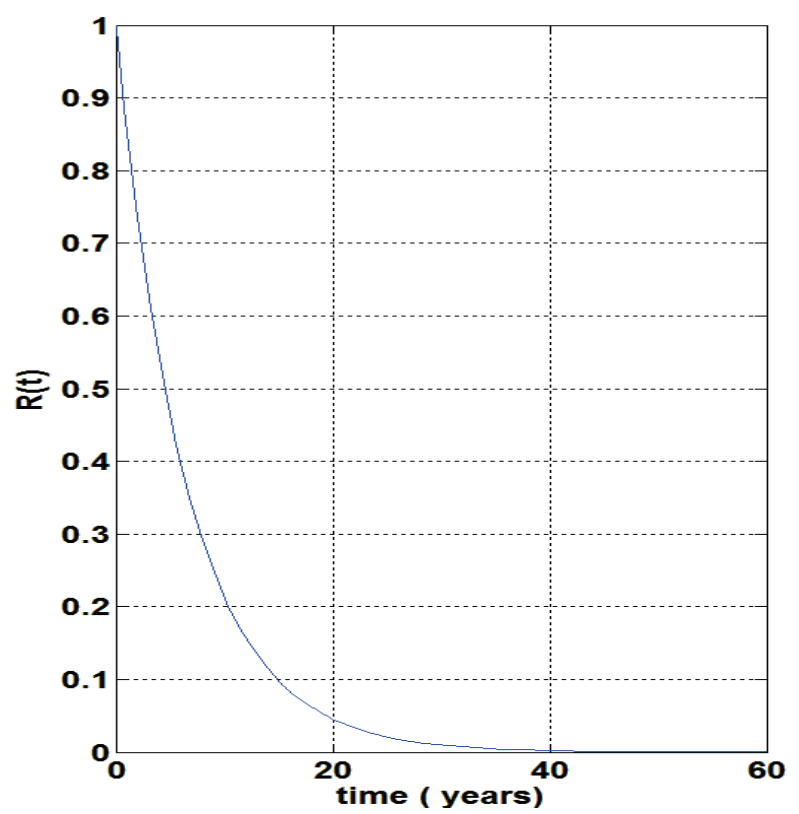

Figure 5 . Reliability of string BoS. 


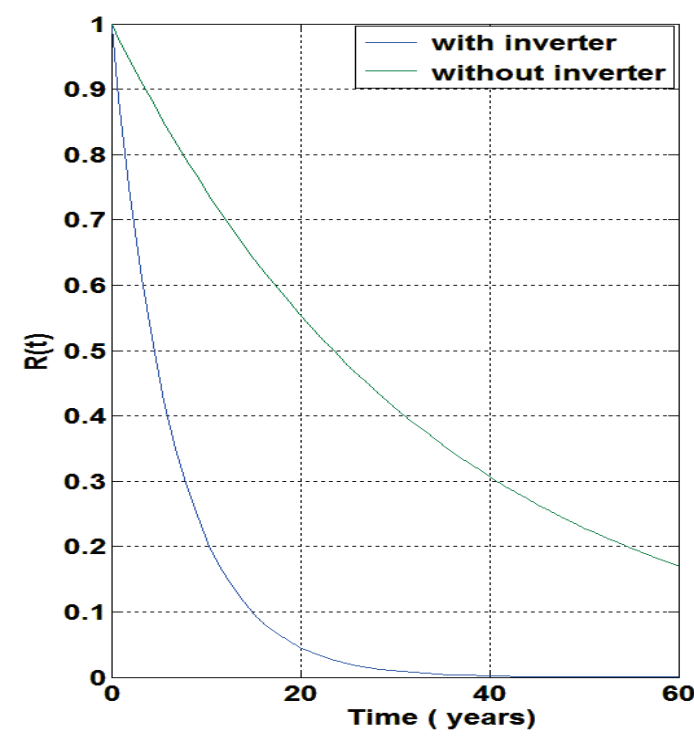

Figure 6. Comparison of string BoS reliability $w$ and $w / o$ inverter.

\section{CRITICALITY ANALYSIS OF PV INVERTER}

Our past work in [29] considers the PV Inverter (PVI) to be just a component among other BoS components. However, results of $\mathrm{CA}$ on $\mathrm{BoS}$, presented in Figure 3, show that PVI contributes significantly in the failures of BoS. Meanwhile, the main concern of the current studies is quite limited to reliability estimations of PVI and reliability improvements of current PVI [30]-[34].

Therefore, performing a CA on PVI components is very crucial to implement the best preventive measures, based on the prioritization of failure modes for PVI components, in order to limit and avoid the outage modes of PVI and reduce the risk number of PVI in the CA of BoS.

The availability of failure data plays a critical role in determining whether the CA will be qualitative, based on previous failure information or quantitative, based on past experience in the field. Both approaches, however, require an identification of the system components as a first step before carrying out the CA.

A typical three phase PVI includes: IGBT Power modules, cooling fans, control software and DC link capacitors implemented on Printed Circuit Boards (PCBs) in addition to AC \& DC contactors.

A quantitative CA approach is followed up for PVI based on a survey carried out by SunEdison Company that operates more than $600 \mathrm{PV}$ systems in four continents with 1500 in-service inverters from 16 vendors and more than 2.2 million PV modules from 35 manufacturers [35]. The surveyed period is during interval January 2010 and March 2012 for 350 systems. The most significant failure modes of PVI inverters in the SunEdison survey are shown in Table 5. Inverter tickets are issued whenever there is a reported failure with PVI. Accordingly, both the percentage of tickets and $\mathrm{kWh}$ lost reflects the occurrence $(\mathrm{O})$ and severity $(\mathrm{S})$ of CA respectively.

In regards to occurrence, failures modes which have percentage of tickets greater than $30 \%$ are considered very high and almost unavoidable failures, percentage of tickets in between $10 \%$ to $20 \%$ and 20 to $30 \%$ are assigned to occasional and high repeated failures, respectively. Meanwhile, a failure mode which has a ticket percentage less than $10 \%$ represents failures with low occurrence.

The severity of the failure mode is evaluated considering the performance and safety issues resulting from the occurrence of each failure mode. Severity is considered low or minor if the percentage of lost $\mathrm{kWh}$ is less than $10 \%$. It is assigned to moderate, high, and very high rankings when the percentage of lost $\mathrm{kWh}$ reaches $10 \%-20 \%, 20 \%-30 \%$ and more than $30 \%$, respectively.

The detection (D) is measured according to the probability of identifying the failure before the system is affected. This can be carried out through the different field indicators. For instance, the alarming system, visual inspection, and comparing measured parameters of monitoring systems to reference values.

CA is conducted based on both Table 2 and Table 5, and RPN are evaluated in Table 6.

In the detection evaluation, it is worth mentioning that IGBT and PCB are assigned to very low and low detection possibilities, respectively, according to IEC criteria, since both are hard to be detected in the field and several studies are currently available to enhance their detection methods. On the other hand, Control software has the highest detection possibility; because the changes in generated electricity can be easily observed with a strong power and energy metering. Moreover, the protection scheme is tested frequently in the site during the scheduled maintenance activities.

Results of CA in Table 6 show that PCB has the highest RPN compared to the rest of the components. Although it has a low rate of occurrence, its severity is the highest, because the highest percentage of $\mathrm{kWh}$ in SunEdison is assigned to its failures. In addition, it has a high detection ranking since the failure detection possibilities of PCBs in the field are very limited.

Table 5 Frequency of tickets and associated energy loss for each PVI failure mode.

\begin{tabular}{|c|c|c|}
\hline $\begin{array}{c}\text { Specific failure } \\
\text { Area }\end{array}$ & $\begin{array}{c}\text { Percentage of } \\
\text { tickets }\end{array}$ & $\begin{array}{c}\text { Percentage of kWh } \\
\text { lost }\end{array}$ \\
\hline $\begin{array}{c}\text { Control } \\
\text { software }\end{array}$ & $28 \%$ & $15 \%$ \\
\hline PCB board & $13 \%$ & $22 \%$ \\
\hline AC contactors & $12 \%$ & $13 \%$ \\
\hline DC contactor & $4 \%$ & $1 \%$ \\
\hline Fans & $6 \%$ & $5 \%$ \\
\hline IGBT modules & $6 \%$ & $5 \%$ \\
\hline Capacitors & $3 \%$ & $7 \%$ \\
\hline
\end{tabular}

Table 6. CA of PVI.

\begin{tabular}{ccccc}
\hline Component failure & S & O & D & RPN \\
\hline IGBT Power Module & 3 & 3 & 7 & 63 \\
DC link Capacitor & 3 & 2 & 5 & 30 \\
AC/DC contactors & 6 & 5 & 5 & 150 \\
Cooling fans & 4 & 3 & 4 & 48 \\
PCB & 7 & 4 & 6 & 168 \\
Control software & 6 & 7 & 3 & 126 \\
\hline
\end{tabular}


Meanwhile, AC/DC contactors recorded the second highest RPN because of their high assigned severity value in SunEdison survey. Improper operation of the contactor subjects the human's life to danger and contributes to fault propagation in the grid. In the field, AC/DC contactors, generally, have moderate detection facility during routine protection tests only.

Control software has the third highest detection possibility. Although the failure detection of control software can be easily detected in the field.

The IGBT power module has a quite moderate RPN. The IGBT power module has the highest detection ranking since it is generally quite difficult in the field to detect its failure. However, both their recorded failures occurrence and the percentage of losses $\mathrm{kWh}$ in the SunEdison survey are moderate compared to other failures. Consequently, the IGBT order is the fourth in the priority.

Both cooling fans and DC link capacitors have the lowest RPN. In the SunEdison survey their failures have insignificant impact on power interruption, and they have low failure frequency of occurrence as well.

In addition, both cooling fans and DC link capacitors have high possibilities to be detected in the field. For instance the IPC-9591 standard [36] specified six symptoms for cooling fans' failures in the field: shaft rotational speed reduction, current consumption increase, loud noise, incorrect or erratic operation of electronic interface, visible cracking of the structure, and visible leakage of lubricants. On the other side, the DC link capacitor symptoms of failures can be detected through RF noise during operation and dissipation factor tests during maintenances besides ESR monitoring during its operation.

\section{CONCLUSIONS}

The root failure causes of PV string BoS are studied in detail through a FMEA approach, and a qualitative CA was conducted in order to prioritize these failure causes, to enhance BoS maintenance activities and decision-making. CA shows that the PV inverter has a high RPN compared to other failure causes and this result was supported by a Markov Process. In the Markov analysis, the MTTF of string BoS is significantly low, around six years, due to the high failure rate of the inverter. The estimated MTTF of string BoS excluding the inverter impact is around 33 years; this can be an accepted value compared to the lifetime of a PV module. Further investigations are conducted on the PVI to prioritize the maintenance activities by determining the RPN of its component failures through quantitative CA.

\section{REFERENCES}

[1] Rosenthal, A.L.; Thomas, M.G.; Durand, S.J., "A ten year review of [20] performance of photovoltaic systems," Photovoltaic Specialists Conference, 1993., Conference Record of the Twenty Third IEEE, pp.1289-1291, 1993.

[2] Gabriele Zini, Christophe Mangeant, Jens Merten," Reliability of [21] large-scale grid-connected photovoltaic systems," Renewable energy journal, Volume 36, Issue 9, September 2011, Pages 2334-2340.

[3] Charki, A.; Bigaud, D., "Availability Estimation of a Photovoltaic System," in Proceedings of Reliability and Maintainability Symposium (RAMS), pp.1-5, 28-31 Jan. 2013.

[4] Alessandra Colli," Failure mode and effect analysis for photovoltaic systems," Renewable and Sustainable Energy Reviews, Volume 50, Pages 804-809, October 2015.
[5] Catelani, M.; Ciani, L.; Cristaldi, L.; Faifer, M.; Lazzaroni, M.; Khalil, M., "Toward a new definition of FMECA approach," in Instrumentation and Measurement Technology Conference (I2MTC), 2015 IEEE International, vol., no., pp.981-986, 11-14 May 2015

[6] Cipriani, G.; Di Dio, V.; La Manna, D.; Miceli, R.; Galluzzo, G.R., "Technical and economical comparison between different topologies of PV plant under mismatch effect," in Ninth International Conference on Ecological Vehicles and Renewable Energies (EVER), pp.1-6, 25-27 March 2014.

[7] AN3432 Application note, How to choose a bypass diode for a silicon panel junction box, September 2011. Available on http://www.st.com

[8] Neelkanth G. Dhere; Narendra Shiradkar ; Eric Schneller and Vivek Gade" The reliability of bypass diodes in PV modules ", Proc. SPIE 8825, Reliability of Photovoltaic Cells, Modules, Components, and Systems VI, 88250I (September 24, 2013); doi:10.1117/12.2026782; http://dx.doi.org/10.1117/12.2026782

[9] M.C. Alonso-García, J.M. Ruíz," Analysis and modelling the reverse characteristic of photovoltaic cells," Solar Energy Materials and Solar Cells, Vol. 90, issue 7-8, pp. 1105-1120, May 2006.

[10] Silvestre S et al., "Study of bypass diodes configuration on PV modules, "applied energy, Vol. 86, issue 9, pp. 1632-1640, 2009.

[11] Frank Jackson, Planning and Installing Photovoltaic Systems: A guide for installers, architects, and engineers, Deutsche Gesellschaft Für Sonnenenergie,2nd edition, 2008.

[12] Shunfeng Cheng; Tom, K.; Pecht, M., "Failure Precursors for Polymer Resettable Fuses," IEEE Transactions on Device and Materials Reliability, vol.10, no.3, pp.374-380, Sept. 2010.

[13] Jing Zhao; Shan-Shan Cao; Yu-Liang Dong; Hong-Wei Zhang; Jian Gong; Qiang Xie, "Analysis of typical failure modes and causes for space thick film fuse," 2013 International Conference on Quality, Reliability, Risk, Maintenance, and Safety Engineering (QR2MSE), pp.1051-1055, 15-18 July 2013.

[14] IEEE Std C37.100-1992, IEEE Standard Definitions for Power Switchgear, 1992.

[15] ABB, technical application papers No.10: photovoltaic plants, Vol.10, 2011

[16] Kuang Sheng; Finney, S.J.; Williams, B.W., "Thermal stability of IGBT high-frequency operation," IEEE Transactions on Industrial Electronics, vol.47, no.1, pp.9-16, Feb 2000.

[17] Thebaud, J.-M.; Woirgard, E.; Zardini, C.; Sommer, K.-H., "Thermal fatigue resistance evaluation of solder joints in IGBT power modules for traction applications," in proceedings of 2000 IEEE 31st Annual on Power Electronics Specialists Conference, 2000. PESC 00. vol.3, pp.1285-1290 vol.3, 2000.

[18] Do, M.T.; Auge, J.L.; Lesaint, O., "Partial discharges in silicone gel in the temperature range $20-150 \hat{A}^{\circ} \mathrm{C}, " 2006$ IEEE Conference on Electrical Insulation and Dielectric Phenomena, pp.590-593, 15-18 Oct. 2006.

[19] R. Wu, F. Blaabjerg, H. Wang, M. Liserre," Overview of catastrophic failures of freewheeling diodes in power electronic circuits," European Symposium on Reliability of Electron Devices, Failure Physics and Analysis, Microelectronics Reliability, Volume 53, Issues 9-11, Pages 1169-1828, September-November, 2013.

Yao Bin; Lu Yudong; Luo Daojun, "Key failure modes of solder joints on HASL PCBs and root cause analysis," 2013 14th International Conference on Electronic Packaging Technology (ICEPT), pp.742-745, 11-14 Aug. 2013.

M. Khalil, L. Cristaldi, M. Faifer," FMECA Analysis for the Assessing of Maintenance Activity for Power Transformers," Proceedings of Maintenance Performance Measurement and Management (MPMM2014), pp. 21-26, Coimbra, Portugal, 4-5 Sept., 2014.

[22] Marvin Rausand, Arnljot Høyland, System Reliability Theory: Models, Statistical Methods, and Applications, 2nd edition, wiley, 2004. ISBN: 978-0-471-47133-2.

[23] IEC-61165, application of Markov techniques, 2nd Ed., 2007. 
[24] IEC-61508, functional safety of electrical/ electronic/ programmable electronic safety- related systems, 2nd Ed., 2010.

[25] A review of PV inverter technology cost and performance projections, Navigant Consulting, Burlington, MA, NREL subcontract Rep. NREL/SR-620-38771, Jan. 2006.

[26] Reliability prediction of electronic equipment, MIL-HDBK-217F, 217F Notice 1, 217F Notice 2

[27] Gabriele Zini, Christophe Mangeant, and Jens Merten," Reliability of large-scale grid0.-connected photovoltaic systems," Renewable Energy, Vol. 36, issue 9, pp. 2334-2340, 2011.

[28] Charki, A.; Bigaud, D., "Availability Estimation of a Photovoltaic System," in proceedings of Reliability and Maintainability Symposium (RAMS), pp.1-5, 28-31 Jan. 2013.

[29] Loredana Cristaldi, Mohamed Khalil, Payam Soulatiantork "Reliability assessment of PV BoS" in proceeding of IMEKO TC10 Workshop on Technical Diagnostics, Advanced measurement tools in technical diagnostics for, systems' reliability and safety, Milan, Italy, June, 2016.

[30] S. Harb and R. S. Balog, "Reliability of Candidate Photovoltaic Module-Integrated-Inverter (PV-MII) Topologies-A Usage Model Approach," in IEEE Transactions on Power Electronics, vol. 28, no. 6, pp. 3019-3027, June 2013.
[31] A. Pregeli, M. Begovic and A. Rohatgi, "Impact of inverter configuration on PV system reliability and energy production," IEEE Photovoltaic Specialists Conference, pp. 1388-1391, 2002.

[32] J. M. Fife, M. Scharf, S. G. Hummel and R. W. Morris, "Field reliability analysis methods for photovoltaic inverters," IEEE Photovoltaic Specialists Conference (PVSC), pp. 002767002772, 2010

[33] Battistelli, L.; Chiodo, E.; Lauria, D., "Bayes assessment of photovoltaic inverter system reliability and availability," in proceedings of International Symposium on Power Electronics Electrical Drives Automation and Motion (SPEEDAM), June 2010

[34] Z. J. Ma and S. Thomas, "Reliability and maintainability in photovoltaic inverter design," Reliability and Maintainability Symposium (RAMS), Lake Buena Vista, FL, pp. 1-5, 2011.

[35] A. Golnas," PV System Reliability: An Operator's Perspective," IEEE journal of Photovoltaic, vol. 3, issue 1, pp. 416-421, 2013.

[36] Hyunseok Oh, Tadahiro Shibutani ,Michael Pecht," Precursor monitoring approach for reliability assessment of cooling fans," Journal of inteeligent manufacturing, vol.23, pp. 173-179, 2012. 